\title{
Physical possibilities in the treatment of chronic abdominal pain in patients with peritoneal adhesions
}

\author{
JAROSŁAW PASEK ${ }^{1,2, A, ~ B, ~ D-F, ~ M I C H A ~} Ł$ SENEJKO 2, A, c, D, F, GRZEGORZ CIEŚLAR ${ }^{2, ~ A-E ~}$ \\ ORCID ID: 0000-0001-6181-337X \\ ${ }^{1}$ Institute of Physical Education Tourism and Physiotherapy, University of Jan Długosz in Częstochowa, Poland \\ ${ }^{2}$ Department of Internal Medicine, Angiology and Physical Medicine, School of Medicine with the Division \\ of Dentistry in Zabrze, Medical University of Silesia, Katowice, Poland
}

A - Study Design, B - Data Collection, C - Statistical Analysis, D - Data Interpretation, E - Manuscript Preparation, F - Literature Search, G - Funds Collection

\begin{abstract}
Summary Background. The most intensive pains suffered by patients after surgical interventions are caused by post-operative peritoneal adhesions, which are incorrect connective tissue connections formed on or among internal organs and tissues in the abdominal cavity. These adhesion-related pains are resistant to analgesic treatment and often persist for many years.

Objectives. In this trial, the estimation of the efficacy of combined treatment with the use of two variable magnetic field related therapeutic methods (magnetotherapy and magnetostimulation) in the treatment of 119 patients with chronic abdominal pains caused by numerous post-operative peritoneal adhesions was performed.

Material and methods. 67 patients from the examined group were subjected to two series of 20 daily procedures of exposure to variable magnetic fields in the form of magnetotherapy and magnetostimulation, while 52 patients from the comparison group were subjected to sham exposure, during which no magnetic field was generated in the applicators. Prior to the therapeutic cycle and after its completion, the assessment of pain intensity, with the use of the Visual Analogue Scale (VAS), and subjective estimation of quality of life, by means of the EuroQol Scale, were performed.

Results. In patients from the examined group, a significant decrease in pain intensity, according to the VAS, and a significant improvement of life quality level, on the EuroQol Scale, in comparison to initial values, was achieved $(8.0 \pm 1.1$ vs $2.3 \pm 1.0$ points, and 30.2 \pm 14.1 vs $86.2 \pm 8.5$ points, respectively $(p<0.05)$; while in the control group, no statistically significant changes of the estimated parameters were observed.

Conclusions. Magnetotherapy and magnetostimulation are efficient therapeutic methods in the case of patients with long-lasting abdominal pain related to peritoneal adhesions, enabling an improvement in their life quality (regardless of gender and age). Taking into account that magnetotherapy and magnetostimulation are not applicable in primary care, family doctors should consider a consultation with a physical therapy specialist in order to prescribe a cycle of physical treatment with the use of these methods in the case of such patients with drug-resistant abdominal pain caused by diagnosed postoperative peritoneal adhesions.

Key words: abdominal pain, magnetic fields, tissue adhesions, therapeutics.
\end{abstract}

Pasek J, Senejko M, Cieślar G. Physical possibilities in the treatment of chronic abdominal pain in patients with peritoneal adhesions. Fam Med Prim Care Rev 2019; 21(2): 124-129, doi: https://doi.org/10.5114/fmpcr.2019.84548.

\section{Background}

Post-operative adhesions are incorrect connective tissue connections formed on or between internal organs and tissues in the abdominal cavity. They occur in about $5-14 \%$ of surgical patients. Abdominal adhesions very frequently occur after operations executed in the lower part of the abdominal cavity (surgical interventions affecting intestines, laparoscopy, gynecological operations) [1]. Sometimes peritoneal adhesions do not cause any complications, yet in many cases, the presence of adhesions causes persistent or recurrent abdominal pains. Moreover, post-operative adhesions located in the hypogastrium in young women can cause infertility [2].

Because the internal organs in the abdominal cavity are covered by a very thin membrane - the peritoneum - often a slight lesion in this membrane during a surgical operation increases the risk of creation of adhesions [3].

The consequences of post-operative adhesions can vary substantially. Some adhesions can exist without resulting in any pains for many years. Unfortunately, many surgical patients with multiple adhesions feel chronic or recurrent pains, which are most often located in the hypogastrium. Diagnosis of the causes of these pains is often very difficult and requires the application of various diagnostic methods, sometimes even repeated hospitalizations. This influences the economic aspect of treatment, which calls for even more attention nowadays. Taking into account the high costs related to the treatment of these patients, incurred due to the necessity of performing numerous long-lasting, repeated surgeries, and the more frequent occurrence of complications, among them the mechanical obstruction of intestines, the fact that the most serious late complications of post-operative adhesions occur in $5 \%$ of patients, in recent years, there have been increasingly interesting investigations of the mechanisms of formation of adhesions, clinical aspects of adhesion-related intestinal obstructions, as well as the development of novel therapeutic methods and prevention procedures concerning this pathology [4-6].

In modern medicine, there are numerous therapeutic opportunities for the treatment of peritoneal adhesions, but they are often not sufficiently efficient $[3,7,8]$. In the last decade, an increasing application of physical therapeutic methods in medicine has been observed, as they can assist the analgesic pharmacological treatment more often. One of the physical methods applied in the treatment of pain of various origins is therapy us- 
ing variable magnetic fields [9]. Depending on the values of the physical parameters of these fields, especially on the value of magnetic field induction, as well as the frequency and course of impulses of magnetic field, therapeutic methods using variable magnetic field are classified in physical medicine as magnetotherapy and magnetostimulation.

Magnetotherapy is a method in which a variable magnetic field with a sinusoidal or rectangular course of impulses, having a frequency below $100 \mathrm{~Hz}$, magnetic field induction in the range $0.1 \mathrm{mT}$ to $30 \mathrm{mT}$ and intensity of electric field comparable to terrestrial electric field level is applied.

Magnetostimulation, in turn, is a method in which "weak" variable magnetic fields, having a saw-like shape of basic impulses, varying in frequency from several to $3,000 \mathrm{~Hz}$ and low values of magnetic field induction from $1 \mathrm{pT}$ to $100 \mu \mathrm{T}$ based on the mechanism of ion cyclotron resonance is applied [10].

The biological action of variable magnetic fields related to the effect that these fields have on ion currents, as well as upon particles having a specific magnetic moment, results, among others, in changes of sensitivity threshold for free nerve endings or cells capable of contracting. Moreover, the ions under the influence of variable magnetic fields gather in the vicinity of biological barriers, e.g. cell membranes in magnetic field, as a result of which ion polarization occurs (in accordance with the phenomenon of ion cyclotrone resonance - ICR) that cause a change of the intensity of ion transfer diffusion rate between the inside area of the cell and the intercellular space, with a subsequent change in the intercellular concentration of ions as sodium, calcium and potassium. This phenomenon has a significant influence upon the intensity of numerous metabolic processes and the speed of nerve conductivity. So far, the biological effects of magnetic fields that have been confirmed in reliable scientific research are vasodilatation, angiogenesis, anticoagulation activity, intensification of the processes of repair and regeneration of soft and bone tissues, as well as anti-oedemic, anti-spastic, anti-inflammatory and analgesic effects [10].

The procedures with the use of variable magnetic fields are well tolerated by patients, and no significant side effects are observed in patients exposed to magnetotherapy and magnetostimulation procedures. Sometimes transient, moderate symptoms, such as: intensification of pain sensation in the early stage of the therapeutic cycle, sensation of fatigue, sweating, itching, tingling sensation and unstable level of arterial blood pressure, occur, especially in patients with increased activity of the vegetative nervous system [10].

The recommended contraindications for magnetotherapy and magnetostimulation procedures are: neoplastic diseases, pregnancy, active form of tuberculosis, hemorrhage from digestive and respiratory tract, hyperthyreosis, electronic implants (e.g. pacemakers), as well as acute infectious diseases, e.g. viral, bacterial and mycotic [10].

\section{Objectives}

The aim of the study is to estimate the efficacy of combined physical treatment with the use of two variable magnetic field related therapeutic methods (magnetotherapy and magnetostimulation) in the treatment of patients with chronic abdominal pains caused by post-operative peritoneal adhesions.

\section{Material and methods}

The study was conducted in accordance with the World Medical Association Declaration of Helsinki: ethical principles for medical research involving human subjects (2000), and its protocol was approved by the Local Ethics Committee of the Medical University of Silesia in Katowice (2015). All qualified patients signed a written consent for participation in this study.

\section{Participants}

The trial was performed on 119 patients having a mean age of $52.3 \pm 16.3$ years (min-max: $13-78$ years) ( 85 women with a mean age of $51.9 \pm 16.2$ years and 34 men with a mean age of $53.5 \pm 16.5$ years), suffering from severe pains in the abdominal cavity caused by numerous post-operative peritoneal adhesions, resistant to pharmacological treatment, randomly divided into 2 groups: the examined group consisting of 67 patients with a mean age of $52.0 \pm 16.2$ years ( 51 women with a mean age of $50.6 \pm 16.7$ years and 16 men with a mean age of $56.5 \pm 14.2$ years) - exposed to a variable magnetic field in the form of magnetotherapy and magnetostimulation procedures - and the comparison group consisting of 52 patients with a mean age of $52.8 \pm 16.6$ years (34 women with a mean age of $53.9 \pm 15.8$ years and 18 men with a mean age of $52.4 \pm 18.3$ years) - subjected to sham exposure.

All patients had been suffering for a few months from severe ("unbearable", as defined by the patients), persistent abdominal pains related to post-operative peritoneal adhesions, after numerous surgical procedures in the hypogastrium area (gynecological and chirurgical types of operations), and pains that were resistant to routine analgesic pharmacological treatment.

The number of surgical interventions executed in patients included in the trial is presented on Figure $1 \mathrm{~A}$ - experimental group and Figure 1B - control group.

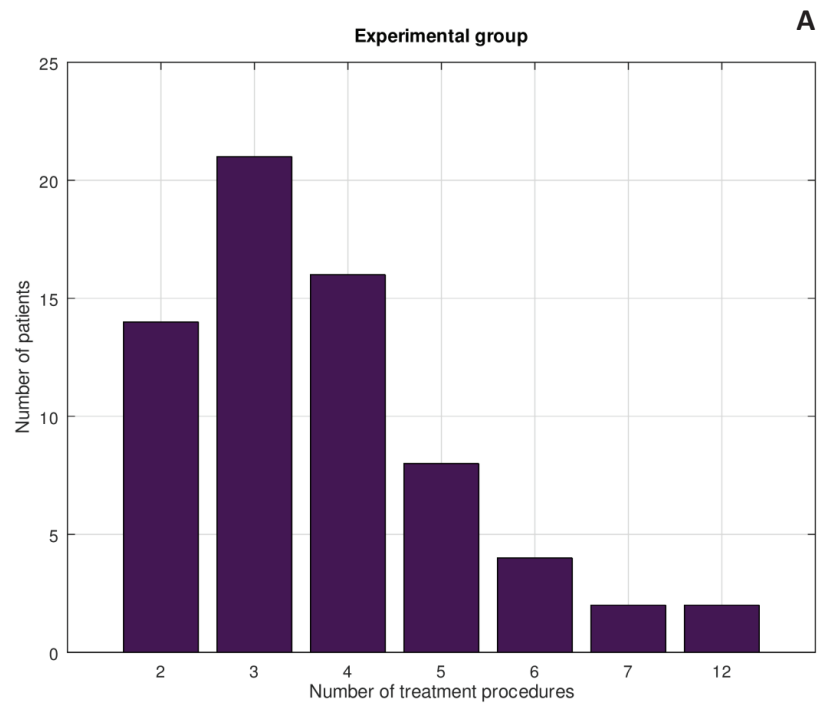

Figure 1A. Number of surgical interventions conducted in patients in experimental group

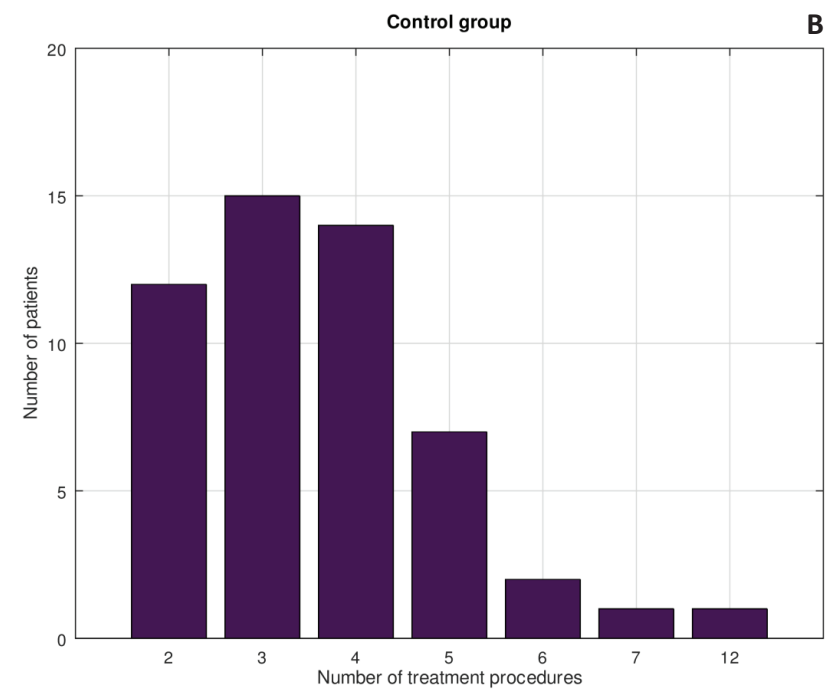

Figure 1B. Number of surgical interventions conducted in patients in control group 
In the objective examination conducted, in all patients, an increase of tension of abdominal integument and distinct muscular defense of the abdominal cavity in painful regions was observed. Before qualification to the trial, an ultrasound and CT examination of the abdominal cavity was performed in order to exclude causes of abdominal pains other than peritoneal adhesions. Based on the performed examination in all patients, no symptoms of active oncological pathology were confirmed.

The criteria of inclusion into the trial were as follows: ultrasound and CT examination before the therapy, patients suffering from abdominal pains for a few months, lack of a positive reaction to applied analgesic pharmacological treatment, patients after numerous post-operative surgical operations of the abdominal and the patients' agreement for participation in the trial. Exclusion examination criteria were: lack of agreement for participation in the examination, different causes of pain ailments in the abdominal cavity, contraindications to magnetic field procedures.

Patients with typical contraindications to magnetotherapy and magnetostimulation, such as: the presence of neoplasm, pregnancy, hyperthyroidism, hemorrhage and hemorrhagic diathesis, tuberculosis, generalized infections, the installation of pace-makers and other electronic implants, were excluded from the trial.

\section{Magnetotherapy and magnetostimulation protocol}

67 patients from the examined group were subjected to a cycle of 20 daily procedures of magnetotherapy with the use of the Viofor JPS System (Med \& Life, Poland), lasting $12 \mathrm{~min}$ utes each (sinusoidal course of impulse, frequency: $40 \mathrm{~Hz}$ and magnetic field indication: $10 \mathrm{mT}$ ), and subsequently - after 4 weeks - to a cycle of 20 daily procedures of magnetostimulation with the use of the Viofor JPS System (Med \& Life, Poland), lasting 12 minutes each (ion cyclotron resonance effect, magnetic field intensity increasing cyclically every 12 seconds to a pre-selected level of 8 , saw-like shape of impulses, frequencies of basic impulses: 180 and $195 \mathrm{~Hz}$, with intensity level: 8 , and magnetic field induction: $100 \mu \mathrm{T}$ ). During the procedure, the painful region of the patient's body was placed inside a cylindrical applicator of devices for magnetotherapy and magnetostimulation, which generate variable magnetic fields.

52 patients qualified to the comparison group were subjected to a cycle of sham exposures, consisting of two series of 20 daily sham exposures to a magnetic field, during which no magnetic field was generated in the applicators of devices for magnetotherapy and magnetostimulation.

\section{Estimation of pain intensity and Quality of Life}

Before the beginning and after the end of a full cycle of procedures, a subjective assessment of pain intensity felt by the patients during the last two months was performed with the use of the Visual Analogue Scale (VAS), in which a score of 0 points is defined as no pain sensation, while a score of 10 points reflected the highest intensity of pain ever experienced by the patient in his life; there was also a subjective estimation of patients' quality of life, measured with the use of the EuroQol Scale, in which 0 points stood for the lowest quality of life, and a score of 100 points reflected the highest quality of life.

\section{Statistical analysis}

All study results, presented as mean value and standard error of the mean (SEM), were subjected to statistical analysis with use of Statistica 7.0 software. The compliance of the distribution of variables with normal distribution was tested by means of the Shapiro-Wilk test, and the statistical significance of differences between the values of particular markers, before and after the therapeutic cycle, was estimated by means of the Mann- Whitney $U$ test and the Wilcoxon test. Differences at a level of $p<0.05$ were considered statistically significant.

\section{Results}

The results of subjective estimation of pain intensity in VAS, before and after the end of a cycle of 40 daily procedures of magnetotherapy and magnetostimulation or a cycle of 40 daily in the examined and comparison group, respectively, are presented in Figure 2.

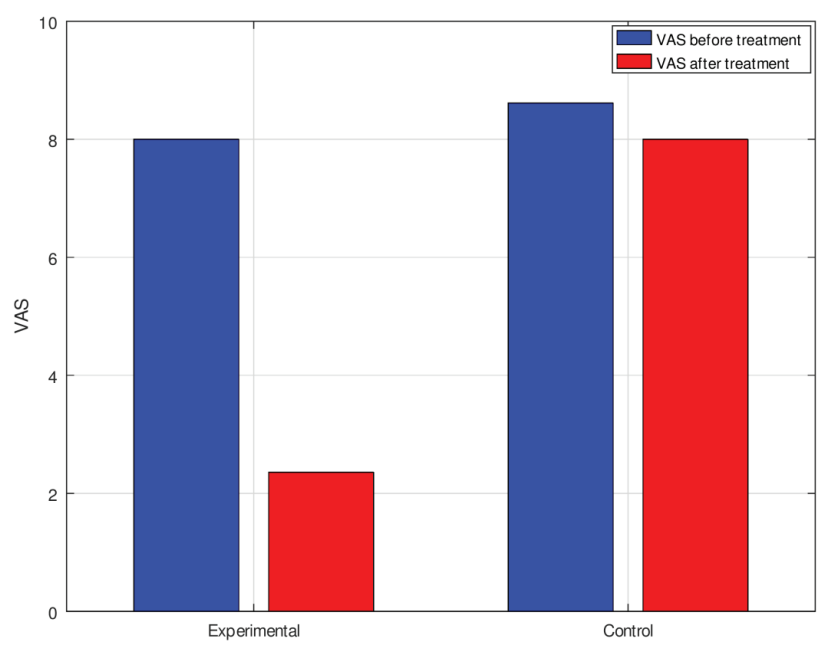

Figure 2. Results of subjective estimation of pain intensity in VAS before and after the end of a cycle of magnetic field therapy, in the examined and comparison group [points]

In the examined group of patients, exposed to variable magnetic fields, a significant decrease (by $66.5 \%$ ) in pain intensity - estimated with the use of VAS - was observed in comparison to the initial value before the beginning of the therapeutic cycle $(8.0 \pm 1.1$ vs $2.3 \pm 1.0$ points, $p<0.05)$, while in the comparison group of patients, subjected to sham exposure, only a slight and insignificant decrease in pain intensity was observed in comparison to the initial value before the beginning of the therapeutic cycle ( $8.6 \pm 0.8$ vs $8.0 \pm 0.4$ points, $p>0.05$ ).

The results of subjective estimation of pain intensity in VAS before and after the end of a cycle of 40 daily procedures of magnetotherapy and magnetostimulation or a cycle of 40 daily in the examined and comparison group, respectively, in relation to gender are presented in Table 1.

\begin{tabular}{|c|c|c|c|c|}
\hline Group & Gender & $\begin{array}{l}\text { Pain } \\
\text { intensity in } \\
\text { VAS before } \\
\text { treatment } \\
\text { [points] }\end{array}$ & $\begin{array}{l}\text { Pain } \\
\text { intensity in } \\
\text { VAS after } \\
\text { treatment } \\
\text { [points] }\end{array}$ & $\begin{array}{l}\text { Statistical } \\
\text { significance } \\
\text { (p) }\end{array}$ \\
\hline \multirow{2}{*}{$\begin{array}{l}\text { Examined } \\
\text { group }\end{array}$} & men & $7.7 \pm 0.9$ & $2.2 \pm 0.9$ & $p<0.05$ \\
\hline & women & $8.1 \pm 1.2$ & $2.4 \pm 1.0$ & $p<0.05$ \\
\hline \multirow{2}{*}{$\begin{array}{l}\text { Comparison } \\
\text { group }\end{array}$} & men & $8.6 \pm 0.9$ & $7.9 \pm 0.4$ & $p>0.05$ \\
\hline & women & $8.6 \pm 0.9$ & $8.0 \pm 0.5$ & $p>0.05$ \\
\hline
\end{tabular}

In the examined group of patients, exposed to variable magnetic fields, a significant decrease in pain intensity - estimated with the use of VAS - in both genders was observed in comparison to the initial value before the beginning of the therapeutic cycle, while in the comparison group of patients, subjected to sham exposure, only a slight and insignificant decrease in pain intensity in both genders was observed in comparison to the initial value before the beginning of the therapeutic cycle. 
The results of subjective estimation of pain intensity in VAS before and after the end of a cycle of 40 daily procedures of magnetotherapy and magnetostimulation or a cycle of 40 daily in the examined and comparison group, respectively, are presented in Table 2.

\begin{tabular}{|c|c|c|c|c|}
\hline Group & $\begin{array}{l}\text { Age } \\
\text { interval } \\
\text { [years] }\end{array}$ & \begin{tabular}{|l} 
Pain \\
intensity in \\
VAS before \\
treatment \\
[points]
\end{tabular} & \begin{tabular}{|l} 
Pain \\
intensity in \\
VAS after \\
treatment \\
[points]
\end{tabular} & \begin{tabular}{|l|} 
Statistical \\
significance \\
$(p)$
\end{tabular} \\
\hline \multirow{3}{*}{$\begin{array}{l}\text { Examined } \\
\text { group }\end{array}$} & $10-30$ & $8.2 \pm 1.6$ & $1.9 \pm 0.9$ & $p<0.05$ \\
\hline & $31-60$ & $8.0 \pm 1.1$ & $2.5 \pm 1.0$ & $p<0.05$ \\
\hline & 61-80 & $7.9 \pm 1.0$ & $2.1 \pm 0.9$ & $p<0.05$ \\
\hline \multirow{3}{*}{$\begin{array}{l}\text { Comparison } \\
\text { group }\end{array}$} & $10-30$ & $8.6 \pm 0.5$ & $8.0 \pm 0.0$ & $p>0.05$ \\
\hline & $31-60$ & $8.5 \pm 1.0$ & $8.0 \pm 0.5$ & $p>0.05$ \\
\hline & $61-80$ & $8.8 \pm 0.8$ & $8.1 \pm 0.4$ & $p>0.05$ \\
\hline
\end{tabular}

In the examined group of patients, exposed to variable magnetic fields, a significant decrease in pain intensity - estimated with the use of VAS - in all age intervals was observed in comparison to the initial value before the beginning of the therapeutic cycle, while in the comparison group of patients, subjected to sham exposure, only a slight and insignificant decrease in pain intensity in all age intervals was observed in comparison to the initial value before the beginning of the therapeutic cycle.

The results of self-estimation of quality of life in the EuroQol scale before and after the end of a cycle of 40 daily procedures of magnetotherapy and magnetostimulation or a cycle of 40 daily sham-exposures in the examined group and comparison group, respectively, are presented in Figure 3.

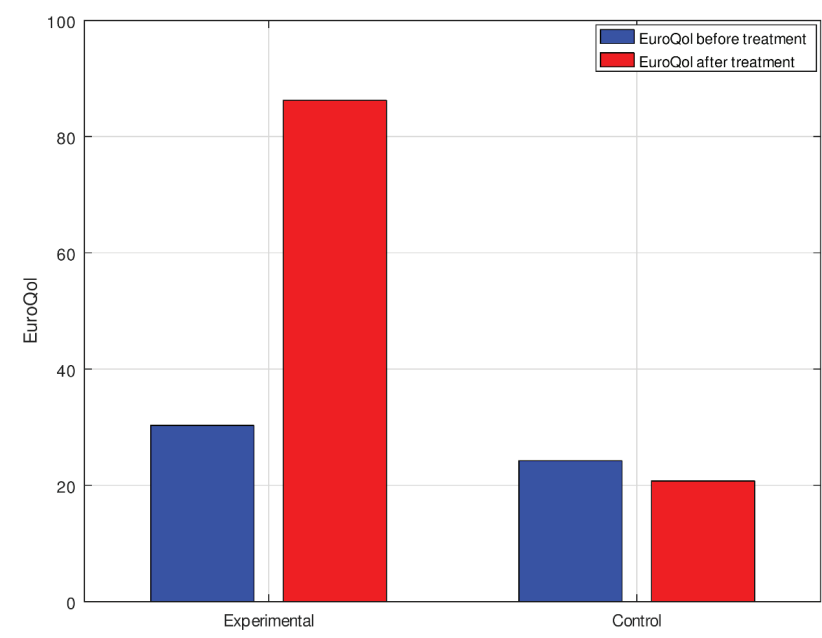

Figure 3. Results of self-estimation of quality of life in the EuroQol scale before and after the end of a cycle of magnetic field therapy, in the examined and comparison group [points]

In the examined group of patients, exposed to variable magnetic fields, a significant improvement of quality of life - indicated by a significant increase in score in the EuroQol scale - was observed in comparison to the initial value before the beginning of the therapeutic cycle $(30.2 \pm 14.1$ vs $86.2 \pm 8.5$ points, $p<0.05$ ), while in the comparison group of patients, subjected to sham exposure, a slight, yet insignificant deterioration of quality of life was observed in comparison to the initial value before the beginning of the therapeutic cycle ( $24.2 \pm 8.7$ vs 20.7 \pm 6.2 points, $p>0.05$ ).
The results of self-estimation of quality of life in the EuroQol scale before and after the end of a cycle of 40 daily procedures of magnetotherapy and magnetostimulation or a cycle of 40 daily sham-exposures in the examined group and comparison group, respectively, in relation to gender are presented in Table 3.

\begin{tabular}{|c|c|c|c|c|}
\hline Group & Gender & $\begin{array}{l}\text { Quality of } \\
\text { life in } \\
\text { EuroQol } \\
\text { scale before } \\
\text { treatment } \\
\text { [points] }\end{array}$ & $\begin{array}{l}\text { Qual- } \\
\text { ity of life } \\
\text { in EuroQ.ol } \\
\text { scale after } \\
\text { treatment } \\
\text { [points] }\end{array}$ & $\begin{array}{l}\text { Statistical } \\
\text { signifi- } \\
\text { cance } \\
(p)\end{array}$ \\
\hline \multirow{2}{*}{$\begin{array}{l}\text { Examined } \\
\text { group }\end{array}$} & men & $34.7 \pm 14.3$ & $85.9 \pm 10.2$ & $p<0.05$ \\
\hline & women & $28.9 \pm 13.9$ & $86.4 \pm 8.1$ & $p<0.05$ \\
\hline \multirow{2}{*}{$\begin{array}{l}\text { Comparison } \\
\text { group }\end{array}$} & men & $24.1 \pm 8.6$ & $20.6 \pm 6.4$ & $p>0.05$ \\
\hline & women & $24.2 \pm 8.9$ & $20.9 \pm 6.2$ & $p>0.05$ \\
\hline
\end{tabular}

In the examined group of patients, exposed to variable magnetic fields, a significant improvement of quality of life - indicated by a significant increase in score in the EuroQol scale - in both genders was observed in comparison to the initial value before the beginning of the therapeutic cycle $(30.2 \pm 14.1$ vs $86.2 \pm 8.5$ points, $p<0.05$ ), while in the comparison group of patients, subjected to sham exposure, a slight, yet insignificant deterioration of quality of life in both genders was observed in comparison to the initial value before the beginning of the therapeutic cycle ( $24.2 \pm 8.7$ vs $20.7 \pm 6.2$ points, $p>0.05$ ).

The results of self-estimation of quality of life in the EuroQol scale before and after the end of a cycle of 40 daily procedures of magnetotherapy and magnetostimulation or a cycle of 40 daily sham-exposures in the examined group and comparison group, respectively, in relation to age are presented in Table 4.

Table 4. Results of self-estimation of quality of life in the

EuroQol scale before and after the end of a cycle of magnetic field therapy, in the examined and comparison group in relation to age [points]

\begin{tabular}{|l|l|l|l|l|}
\hline Group & $\begin{array}{l}\text { Age } \\
\text { interval } \\
\text { [years] }\end{array}$ & $\begin{array}{l}\text { Quality of } \\
\text { life in the } \\
\text { EuroQol } \\
\text { scale before } \\
\text { treatment } \\
\text { [points] }\end{array}$ & $\begin{array}{l}\text { Quality of } \\
\text { life in the } \\
\text { EuroQol } \\
\text { scale after } \\
\text { treatment } \\
\text { [points] }\end{array}$ & $\begin{array}{l}\text { Statistical } \\
\text { signifi- } \\
\text { cance } \\
(p)\end{array}$ \\
\hline \multirow{2}{*}{$\begin{array}{l}\text { Examined } \\
\text { group }\end{array}$} & $10-30$ & $28.9 \pm 17.6$ & $91.9 \pm 6.0$ & $p<0.05$ \\
\cline { 2 - 5 } & $31-60$ & $30.0 \pm 14.7$ & $84.5 \pm 4.8$ & $p<0.05$ \\
\cline { 2 - 5 } & $61-80$ & $29.6 \pm 12.0$ & $87.3 \pm 6.2$ & $p<0.05$ \\
\hline \multirow{2}{*}{$\begin{array}{l}\text { Comparison } \\
\text { group }\end{array}$} & $10-30$ & $22.5 \pm 4.6$ & $21.3 \pm 3.5$ & $p>0.05$ \\
\cline { 2 - 6 } & $31-60$ & $25.6 \pm 9.7$ & $21.1 \pm 7.0$ & $p>0.05$ \\
\cline { 2 - 6 } & $61-80$ & $22.9 \pm 8.5$ & $20.0 \pm 6.1$ & $p>0.05$ \\
\hline
\end{tabular}

In the examined group of patients, exposed to variable magnetic fields, a significant improvement of quality of life - indicated by a significant increase in score in the EuroQol scale - in all age intervals was observed in comparison to the initial value before the beginning of the therapeutic cycle $(30.2 \pm 14.1$ vs $86.2 \pm 8.5$ points, $p<0.05$ ), while in the comparison group of patients, subjected to sham exposure, a slight, yet insignificant deterioration of quality of life in all age intervals was observed in comparison to the initial value before the beginning of the therapeutic cycle $(24.2 \pm 8.7$ vs $20.7 \pm 6.2$ points, $p>0.05)$.

All patients treated with both therapeutic methods tolerated the procedures performed well, and no side-effects of treatment were observed. 


\section{Discussion}

Despite conducting intensive clinical and experimental research, there is still no generally accepted effective method of treatment for post-operative adhesions found. Pharmacological treatment kindles some hope, but has so far not clearly shown any advantages resulting from its application. In turn, attentive anatomical surgery, reliable hemostasis, strict surgical asepsis and the selection of optimal surgical methods with the application of less invasive procedures leads only to the reduction of number of post-operative complications [11-14].

So far, many surgical methods have been described aiming at the prevention of excessive creation of peritoneal adhesions (folding of the intestine wall, splinting of the intestine and leaving the peritoneum open in the post-operative course), but these methods result in the necessity to perform further operational interventiona $[15,16]$. This is why the avoidance of a lesion of the peritoneum during an operation is considered to be the most efficient method of preventing the creation of post-operative adhesions $[1,17]$.

In the present study, we confirmed that the application of variable magnetic fields (in the form of two different therapeutic methods) for the treatment of patients with peritoneal adhesions provides satisfactory therapeutic effects and generally results in almost complete regression of abdominal pain. Though the therapeutic process was long-lasting and time-consuming, the obtained effects of treatment significantly contributed to the improvement of the quality of life of patients treated with magnetic fields (Quality of Life) [12, 15].

The observed anti-nociceptive effect was probably caused by the reduction of nerve impulse conduction in afferent nerve fibers, due to the hyper-polarization of neuron membranes, as well as by the increase of synthesis and secretion of endogenous opiates (beta-endorphins) in the central nervous system, resulting in raising the threshold of pain sensation $[8,17]$.

The slight, and statistically insignificant, decrease in pain intensity observed in patients from the control group was prob- ably related to a subjective placebo effect regarding the psychological value of participation in a novel physical therapy.

In patients treated with variable magnetic fields, a distinct reduction of muscular hypertonia in abdominal integument was also obtained. The mechanism of this antiphlogistic and antispastic effect could be related to the positive impact of variable magnetic fields on structures of liquid crystals in muscle membranes, resulting in the change of permeability of membrane ion channels, especially for calcium and natrium ions, and modification of their penetration between the cytoplasm and extracellular space, which is responsible for muscular tension. In turn, the regenerative effect of both therapeutic methods is probably related to the influence of applied variable magnetic fields on the muscular coat of blood vessels, resulting in decreased tension of smooth muscles and intensification of the angiogenesis, with subsequent improvement of tissue perfusion [7, 9].

\section{Limitations of the study}

There were no follow-up observations in this study, but the authors, in order to estimate how long the obtained analgesic effect lasts, in the near future plan to perform a subsequent trial with a follow-up lasting from 1 to 12 months.

\section{Conclusions}

1. Magnetotherapy and magnetostimulation are efficient therapeutic methods in patients with long-lasting abdominal pain related to peritoneal adhesions, enabling the improvement of their quality of life (regardless of gender and age).

2. Taking into account that magnetotherapy and magnetostimulation are not applicable in primary care, family doctors should consider in the case of patients with drug-resistant abdominal pain caused by diagnosed post-operative peritoneal adhesions a consultation with a physical therapy specialist in order to prescribe a cycle of physical treatment with the use of these methods.

Source of funding: This work was funded from the authors' own resources.

Conflicts of interest: The authors declare no conflicts of interest.

\section{References}

1. Güney G, Kaya C, Oto G, et al. Effects of quercetin and surgical for preventing adhesions after gynecological surgery: a rat uterine horn model. J Obstet Gynaecol Res 2017; 43(1): 179-184.

2. Koninckx PR, Gomel V, Ussia A, et al. Role of the peritoneal cavity in the prevention of postoperative adhesions, pain, and fatigue. Fertil Steril 2016; 106(5): 998-1010.

3. Li XD, Xia DL, Shen LL, et al. Effect of "phase change" complex on postoperative adhesion prevention. J Surg Res 2016; 202(1): 216-224.

4. Morawski B, Nawrot I, Klonowski W, et al. Peritoneal adhesions as a cause of mechanical small bowel obstruction based on own experience. Pol Przegl Chir 2015; 86(11): 523-531.

5. Smolarek S, Shalaby M, Paolo Angelucci G, et al. Small-bowel obstruction secondary to adhesions after open or laparoscopic colorectal surgery. JSLS 2016; 20(4): 201-216.

6. Lin LX, Yuan F, Zhang HH, et al. Work of separation - a method to assess intraperitoneal adhesion and healing of parietal peritoneum in an animal model. Clin Biomech 2016; 41: 82-86.

7. Hoare T, Yeo Y, Bellas E, et al. Prevention of peritoneal adhesions using polymeric rheological blends. Acta Biomater 2014; 10(3): 1187-1193.

8. Gomel V, Koninckx PR. Microsurgical principles and postoperative adhesions: lessons from the past. Fertil Steril 2016; 106(5): 1025$-1031$.

9. Pasek J, Sieroń A. Possibilities of physical medicine interventions in the treatment of wound of tarsal joint. Acta Angiologica 2015; 4: 132-135.

10. Sieroń A, Cieślar G, Stanek A, eds. Pole magnetyczne i światło w medycynie i fozjoterapii. Bielsko-Biała: $\alpha$-medica press; 2013 (in Polish).

11. Rice AD, King R, Reed ED, et al. Manual physical therapy for non-surgical treatment of adhesion-related small bowel obstructions: two case reports. J Clin Med 2013; 2(1): 1-12.

12. Oh J, Kuan KG, Tiong LU, et al. Recombinant human lubricin for prevention of postoperative intra-abdominal adhesions in a rat model. J Surg Res 2017; 208: 20-25.

13. Marshall CD, Hu MS, Leavitt T, et al. Creation of abdominal adhesions in mice. J Vis Exp 2016; 27: 114-118.

14. Diamond MP. Reduction of postoperative adhesion development. Fertil Steril 2016; 106(5): 994-997.

15. Koninckx PR, Gomel V. Introduction: quality of pelvic surgery and postoperative adhesions. Fertil Steril 2016; 106(5): 991-993.

16. Alonso Jde M, Alves AL, Watanabe MJ, et al. Peritoneal response to abdominal surgery: the role of equine abdominal adhesions and current prophylactic strategies. Vet Med Int 2014; 279: 1-8. 
17. van Baal JO, Van de Vijver KK, Nieuwland R, et al. The histophysiology and pathophysiology of the peritoneum. Tissue Cell 2016; 148-153.

Tables: 4

Figures: 3

References: 17

Received: 11.10 .2018

Reviewed: 17.10.2018

Accepted: 22.11.2018

Address for correspondence:

Jarosław Pasek, PhD

Katedra i Oddział Kliniczny Chorób Wewnętrznych,

Angiologii i Medycyny Fizykalnej

Śląski Uniwersytet Medyczny w Katowicach

ul. Stefana Batorego 15

41-902 Bytom

Polska

Tel.: +48 32 786-16-30

E-mail: jarus_tomus@tlen.pl 